\title{
浅谈建筑工程混凝士质量通病与防治
}

\author{
朱娜丽 \\ 新疆赣丰工程建设有限公司 \\ DOI:10.18686/bd.v2i10.1764
}

[摘要] 混凝土是当前建筑工程施工中应用的主要材料, 具有成本低廉、施工工艺简单、强度高等优势, 但是受多种因素的 影响, 混凝土施工经常出现质量问题, 而且出现频率较高, 被行业内部定义为混凝土质量通病, 这些病害虽然威胁较小, 但长时 间得不到有效处理, 病害会逐步升级, 对混凝土结构的稳定与质量产生影响。因此, 对混凝土质量通病的防治十分重要, 文章 对当前建筑工程混凝土施工经常出现的病害进行了总结, 并有针对性的提出防治措施, 以便为建筑工程混凝土施工提供参 考。

[关键词] 建筑工程; 混凝土施工; 质量通病; 防治措施

混凝土在建筑工程中有着重要地位, 而且使用量较大, 经常与钢筋配合使用作为建筑的承重构件, 所以直接关系 到建筑工程的稳定性与安全性, 但是混凝土质量通病的客 观存在对其作用与价值产生了严重的负面影响。因此,在建 筑工程混凝土施工环节中, 必须强化质量意识, 严格遵守工 序以及施工质量规范, 控制质量问题的出现, 而且有效的将 质量问题的防治方法运用到施工中,有效的提升工程质量。

\section{1 露筋与表面不平整问题的防治}

建筑工程混凝土施工过程中出现露筋以及表面不平整 的问题是混凝土中的钢筋裸漏在混凝土表面上, 导致表面 不平。出现露筋这样问题的原因是在施工中混凝土浇筑与 振捣环节出现了问题, 钢筋的垫块使用量不足或振捣的外 力作用导致垫块位移,使钢筋与模板紧贴在一起; 或因钢筋 使用量过大, 导致钢筋密度大, 但是混凝土断面过小, 无法承 载; 或因模板拆除过早; 或因振捣力度小, 混凝土密实度不 足, 出现离析现象等[1]。出现露筋会导致混凝土表面不平整, 但并不单纯是露筋导致的,从施工工艺角度来看, 出现混凝 土表面不平整这种情况是由于施工过程中, 施工人员在完 成混凝土浇筑后, 没有利用工具或其它措施进行抹平, 导致 问题没有被及时发现; 或在材料使用上出现问题,导致混凝 土浇筑过程中出现印痕以及凹陷不平的现象。

对于露筋问题进行防治,可以采取以下手段: 对于露筋 问题, 在混凝土施工环节, 要保障钢筋垫块数量充足, 位置准 确,做好垫块固定工作, 检测保护层的厚度是否符合要求,如 果钢筋使用量较大, 密度较大, 可以选择级配良好的石子卡 到钢筋处, 避免在浇筑过程中外力作用下钢筋出现位移或 变形情况 ${ }^{[2]}$ 。同时,施工前的准备工作也十分重要,并对钢筋 的外观进行检测, 保持表面清洁, 不存在铁锈, 做好防腐工 作。

对于表面不平整问题的防治,可以采取以下手段:严格 的规范施工人员的施工行为, 在完成混凝土浇筑施工中, 要 根据现场放线留取的控制标志进行混凝土表面抹平, 而且 混凝土浇筑完成后要及时进行养护工作, 定时对模板的刚
度以及强度进行检测, 避免模板出现位移或下陷的问题, 当 混凝土强度未达到可承载外力强度之前, 严禁任何人在混 凝土结构上走动。

\section{2 混凝土强度不足的防治}

混凝土强度不足是指施工后的混凝土强度等级与施工 设计要求不符, 这种问题出现的原因主要是施工中使用的 材料质量不达标; 水泥型号使用错误; 水泥出现变质,活性 下降; 配料级配不足, 含泥量大; 混凝土配制中外加剂使用 不合理; 配合比不科学,用水量过高; 混凝土配制中搅拌实 践不充足或搅拌不均匀; 养护不及时、养护手段不合理,拆 模时间不合理等 ${ }^{[3]}$ 。

混凝土强度不足会导致混凝土承载力下降, 从而威胁 建筑的稳定性与安全性。对于这种问题的防治, 要从施工规 划设计中做好严格的管理,并保障施工工艺合理。例如,选择 质量符合施工要求与标准的原材料, 水泥型号正确,性能与 施工要求相符; 按照科学、合理的配合比进行原料配制, 尽 量减少外加剂的使用, 如果必须通过外加剂保障混凝土强 度, 要通过准确的计算, 确定外加剂计量; 保障混凝土摚拌时 间充分、摚拌均匀, 并对摚拌后的混凝土性能进行测试, 强度 不足时要及时采取补强措施进行处理。

\section{3 混凝土麻面的防治}

在混凝土施工中经常发现混凝土表面出现凹坑或麻 点, 这就是麻面问题的体现, 也是混凝土施工中常出现的一 种质量问题, 导致混凝土表面粗糙, 但是不存在露筋问题。出 现麻面问题主要是在施工中浇筑环节使用的模板表面过于 干燥, 浇筑后其会吸收混泥土中的水分, 从而导致混凝土水 分流失过快; 或因施工前未对模板表面进行清洁,导致表面 存在杂物; 或因混凝土振捣力度不足,气泡未排除。

对于麻面问题的防治, 可以采取以下手段: 在浇筑混凝 土之前, 检测模板湿度, 过于干燥要及时酒水, 始终保持模板 表面湿润; 并对模板表面进行清洁,不得出现任何杂物或垃 圾, 尤其是细小的砂砾; 完成浇筑后, 要严格根据施工要求做 好振捣工作, 但是振捣力度要合理控制, 不能过大触碰到模 
板; 振捣应分层进行,保障每层气泡能够全面排出; 此外,麻 面一旦形成, 可以按照混凝土配比, 重新配置砂浆,进行麻面 抹平 ${ }^{[4]}$ 。

\section{4 孔洞的防治}

在施工中预留孔洞或预埋件以及钢筋密度较大的位 置, 混凝土会被材料隔住无法进人到材料形成的较为密闭 空间内, 而且浇筑过程中未分层振擖进行下一层的浇筑, 导 致混凝土内部存在未浇筑到的空间,这就是孔洞。出现孔洞 的原因使混凝土强度不足,振捣工作未做好; 混凝土下料量 过大, 导致混凝土较厚, 振捣器振捣力度不够, 无法保障振捣 充分; 或在孔洞等内部存在杂物,阻挡混凝土的进入[5]。

孔洞的出现导致混凝土出现受力不均的情况, 有效的 防治可以采取以下手段: 在结构相对复杂或钢筋密度较大 的位置,应使用细石混凝土浇筑,并且在浇筑过程中通过分 层振捣的方式保障振捣均匀,混凝土密实度符合标准,从而 保障混凝土能够充分到达模板内部的每个角落; 对于施工 中预留的孔洞,应从下料开始,避免侧漏或出现漏振情况,并 对孔洞进行清理, 彻底清除杂物。如果孔洞已经形成, 可以将 孔洞附近的松散混凝土丵除, 利用清水重新对孔洞进行处 理,使其处于湿润状态,再利用混凝土进行浇筑。

\section{5 建筑工程混凝土质量通病管理}

严格的管理能够有效降低质量通病问题的出现几率, 管理主要包括质量管理与技术管理两部分内容, 通过质量 管理强化施工人员的质量意识, 通过技术管理保障施工技 术的科学性, 从而严格规范施工人员行为。

在质量管理上。施工过程中应由专业的质量检验团队 对混凝土施工的每项内容进行质量检测, 检测主要内容为: 混凝土施工原材料质量,如水泥型号、规格,粗骨料级配、含 泥量等; 并重点注意在原料存放过程中是否出现变质或过 期问题; 施工过程中,对于每项完成施工的内容要进行质量 检测, 检查用料量、混凝土强度等,一旦发现问题, 要及时进 行处理。此外,为了避免质量通病出现, 在施工前要严格对施 工工序进行检查,保障施工工序合理,并严禁任何人在施工 中进行工序调整,如果存在问题,要与上级部门进行沟通, 由 工程总工程师对工序调整进行判断,得到审批后在执行[6]。

在技术质量管理上。从上述质量通病的原因来看,很多 是由于施工技术出现问题导致的, 从施工组织规划设计过
程中要对施工技术给予关注, 结合施工现场的环境与条件 分析施工技术的可操作性, 保障施工技术与施工现场的实 际情况相符, 以此为依据对施工技术的具体应用制定管理 标准，管理人员根据此在施工中对技术的使用情况进行严 格的管理[]。例如,施工技术管理标准中明确规定,在完成混 凝土浇筑工作后, 混凝土不同凝固阶段都要采取相应的养 护措施, 而且给出了拆模的判断标准以及具体的时间范围, 如果施工人员未根据规定进行养护工作或拆模, 管理人员 有权对施工人员做出惩罚, 如果出现质量问题损失也将由 相关负责人承担,而且管理人员也连带受到处罚。

通过管理手段对质量通病进行防治, 不仅可以提升混 凝土施工质量, 在一定程度上提升了混凝土施工水平, 实现 了规范化施工。

\section{6 结束语}

综上所述, 从上述内容可以看出, 混凝土质量通病大多 数是细节上的问题, 但是这些质量问题会影响建筑工程的 品质,而且当建筑运营后, 外作用力会使细小的质量问题升 级、扩大, 导致建筑的安全性受到威胁。因此, 应给予质量通 病高度重视,合理的进行防治,并利用有效的管理手段降低 质量通病出现的几率,从而提升混凝土施工质量。

[参考文献]

[1]陈其永.浅谈建筑工程钢筋混凝土质量通病与防范 策略[J].中国房地产业,2018,27(10):124-125.

[2]翟镜清.探讨混凝土质量通病和预防措施及处理方 法[J].建筑工程技术与设计,2018,30(17):5534.

[3]间毅,封建敏, 张兴茹.阿建筑工程混凝土质量通病 原因及防治对策分析 [J]. 建筑工程技术与设计,2016,24(9): 1195.

[4]季金分. 分析建筑工程混凝土质量通病的对策防治措 施[J].中国科技投资,2017,33(13):66.

[5]田立男, 吴迪. 建筑工程施工中钢筋混凝土质量通病 及控制措施分析[J].建材发展导向(下),2018,25(1):231.

[6]温三太,张云园. 建筑施工中混凝土工程的质量通病 及防治措施分析[J]. 房地产导刊,2018,26(11):73.

[7]杨二勇. 建筑工程混凝土结构质量通病与防治措施 探讨[J].建筑・建材・装饰,2015,21(17):208-209. 